\title{
Effects of Task Conditions and Administrations on Changes in
}

\section{State Motivation}

\author{
Tsutomu Koga ${ }^{1 *}$ \\ ${ }^{1}$ Tokai University, Hiratsuka-shi Kanagawa, Japan \\ *Tsutomu Koga, E-mail: koukoga@ hotmail.com
}

\begin{abstract}
Many traditional motivation studies have argued that trait motivation strongly controls state motivation. This study, however, focuses more on state motivation and attempts to suggest a bottom-up approach whereby stimulating state motivation through the use of tasks has a potential to positively influence trait motivation. As few studies have argued the task administration and condition in relation to changes in state variables, this study deals mainly with task conditions (i.e., closed vs. open tasks) and task administration (i.e., individual vs. pair tasks) with special attention to changes in state motivation, perceived competence, and anxiety. Four sets of narrative writing tasks were designed: individual-closed, individual-open, pair-closed, and pair-open. Before and after each task, students were asked to answer questionnaires measuring the previously mentioned three state variables. The results indicate that (a) learners' motivation, competence, and anxiety were more likely to positively change in pair tasks, (b) before the tasks, individual-tasks were considered more attractive than pair-tasks, and (c) after the tasks, however, learners felt more competent performing pair-tasks than individual-tasks. Based on these results, this study suggests that pair tasks positively influence learners' state variables.
\end{abstract}

\section{Keywords}

motivation, task characteristics, state variables

\section{Introduction}

Traditional motivation studies have heavily focused on motivation in terms of "what", ignoring the importance of "how"; in other words, their primary interest has been in the examinations of what constitutes motivation and what relationships are observed between motivation and achievement, but not in how to enhance motivation and how motivation produced in one situation differs from that produced in a different situation. In fact, only limited research has analyzed how one type of motivation (i.e., trait motivation) differs from the other (i.e., state motivation) in the process of learning (e.g., Gardner \& Tremblay, 1998; Tremblay, Goldberg, \& Gardner, 1995) and what external factors affect motivation so that its level increases (e.g., Julkunen, 2001; Hiromori, 2012). Bearing this tendency in mind, this study attempts to emphasize the "how" side of motivation particularly in relation to task 
characteristics. Tasks have a great deal of potential to both positively and negatively influence learners' task-specific state variables depending on the difficulty, complexity, conditions, and administrations (Robinson, 2001). A way to use or implement different tasks and the way they are administered is totally dependent on a teacher's teaching strategy in class. If we as teachers can grasp the effects of implementation on state variables, we can contribute to successful language learning. The fundamental purpose of this study, thus, is to investigate how learners' state variables change when narrative writing tasks with different task conditions and administrations are assigned to learners.

\section{Previous Studies and Purposes of the Research}

Ever since Gardner (1985) proposed his influential socio-educational model, numerous motivation studies have been conducted to examine relationships among motivational variables (e.g., Taguchi, Magid, \& Papi, 2009) and between motivation and language achievement (e.g., Masgoret \& Gardner, 2003). However, about two decades after Crookes and Schmidt (1991) suggested that motivation plays an important role in the process of classroom language learning, some researchers have started to turn their attention to the dynamic aspects of motivation. Gardner, Masgoret, Tennant and Mihic (2004), for instance, reported that classroom attributes such as anxiety and motivation were more amenable to change than non-classroom attributes such as language aptitude and strategies. Similarly, Koga (2010) discovered that communication apprehension significantly decreased and a sense of cooperativeness positively developed when he created a communicative and cooperative language classroom. Borrowing some ideas from self-determination theory (Deci \& Ryan, 1985), Hiromori (2006) also succeeded in shifting from extrinsic behaviors to intrinsic ones of less motivated learners. More recently, Hiromori (2012) took an innovative approach to foster learner motivation by modifying teaching styles and methods in the middle of a semester based on learners' comments and requests. It is worth noting that Hiromori's study is intriguing in that the teacher actively heard learners' voices and adjusted the classroom to satisfy their needs.

In educational psychology, Boekaerts $(1986,1988)$ divided motivation into two types: trait motivation that refers to one's enduring and stable disposition, and state motivation that represents one's flexible and dynamic disposition. She asserted that this distinction made possible better and more systematic understandings of learner motivation, and that both types of motivation needed to be taken into consideration in meaningful learning contexts. The studies investigating the development of motivation (e.g., Koga, 2010; Hiromori, 2006) challenged the claim that motivation is a stable and fixed disposition (i.e., trait motivation) and successfully counter-argued that motivation can be fostered by educational interventions. However, except for Hiromori (2012), we cannot pinpoint what factor is actually responsible for manipulating motivational variables in the classrooms. This is not only because classroom factors are so complexly intertwined that identifying only one factor is virtually impossible, but also because some studies are not specifically designed to point out the motivational factors due to their main focus placed on other aspects of the classroom variables.

Published by SCHOLINK INC. 
Another exception is research on task motivation where tasks are specifically used to stimulate task-specific motivation. Using three different types of tasks (i.e., an arithmetic task, a reading comprehension task, and a drawing task), Boekaerts (1986) examined how general motivational components (GM), task-specific motivational components (TSM), and SiSAT (i.e., affective conditions affected by task performance) interacted with each other. It was discovered that the correlations between TSM and SiSAT were greater than those between GM and SiSAT. Julkunen (2001) turned his eyes to Boekaerts' model $(1986,1988)$ and was the first one to apply it to FL learning contexts. He examined this model by using closed and open vocabulary tasks in three different task administrations: individual, cooperative, and competitive. Learners' SiSAT 1 was measured just prior to the task engagement and SiSAT 2 immediately after the task. Julkunen hypothesized that the changes in SiSATs would be caused by task conditions (closed and open) and task administration (individual, cooperative, and competitive). The results indicated that the high-proficiency group demonstrated more positive attitudes towards individual- and competitive-closed tasks than the low-proficiency group. The variations in learners' SiSATs were positive in the cooperative tasks, suggesting it is the most effective task administration for both high and low proficiency learners. As for the task condition, he posited that the open tasks were more motivating than the closed tasks.

Gardner and Tremblay (1998) and Tremblay, Goldberg and Gardner (1995) proposed that trait motivation had a strong impact on state motivation, which in turn influenced task performance. Tremblay, Goldberg and Gardner, for instance, suggested the function of state motivation as a mediator between trait motivation and task performance. In other words, trait motivation played a minor role in learning the target language, but it was state motivation which played a major part in task performance. Their suggestions were later empirically supported by Gardner and Tremblay who examined the strength of association between trait and state motivation and task performance by calculating partial correlations. They concluded that trait motivation directly stimulated state motivation and that state motivation affected task performance.

More recently, Kormos and Dörnyei (2004) found that certain motivational variables (e.g., integrativeness, self-confidence, language use anxiety, etc.) were more likely correlated with certain language variables (e.g., quantity of talk including the number of words and turns, accuracy, complexity, etc.) in an argumentative oral task. Language use anxiety, for instance, was negatively correlated with the number of arguments (i.e., number of claims and supports), but no other significant correlation was observed. It is interesting to note that not only task-specific motivational variables (e.g., task attitudes), but also course-related variables (e.g., course attitudes) affected linguistic variables specific to the argumentative task.

The second important finding of this study examined how learners were paired up in the task. Their finding showed that learners with positive task attitudes tended to have a positive influence on less motivated learners. Learners co-constructed task motivation to succeed in the task. Finally, they stated that motivation had a direct effect on the quantity of the product rather than its quality, strongly 
reinforcing the idea of motivation as a driving force.

Although the aforementioned studies give an insight into the relationships between task characteristics and task-specific motivation, two questions remain ambiguous. The first question is related to whether learners' first impressions of a task (e.g., SiSAT 1 in Julkunen (2001)) would vary after they actually perform it (SiSAT 2). Although comparing these two types of state motivation seems to be an interesting topic in individual-difference research, only a few studies in FL/SL learning contexts are found (Julkunen, 2001). Besides, state variables other than state motivation have not been examined based on the SiSAT 1 and SiSAT 2 distinction. Therefore, this study takes into account other important state variables, namely perceived competence and anxiety, which also have a strong impact on task performance.

The second question concerns whether learners' state variables would differ from task condition to task condition. Boekaerts (1986) illustrated the relationships between trait and state motivational components by using tasks in three different areas (i.e., an arithmetic task, a reading comprehension task, and a drawing task). Julkunen (2001) reported that a cooperative open task related to vocabulary learning was effective in terms of motivation, but the task types treated were two different kinds (i.e., categories and three of a kind). Kormos and Dörnyei (2004) mainly showed relationships between task performance and individual difference variables, effects of pairings, and roles of motivation in an argumentative oral task, but did not place an emphasis on the variability of such factors. To clearly examine the effects of task conditions and administration, one possible hole that needs to be filled is realted to control of task type. A study focusing only on "one task type" is necessary. Therefore, this study pinpoints a narrative writing task and discusses how state variables would differ when one task type with different conditions and administration would be assigned. The following six Research Questions (RQs) are established based on these two questions.

RQ 1: To what extent does learners' state motivation differ from before and after performing a task with a different task condition?

RQ 2: To what extent does learners' perceived competence differ from before and after performing a task with a different task condition?

RQ 3: To what extent does learners' state anxiety differ from before and after performing a task with a different task condition?

RQ 4: To what extent does learners' state motivation vary from task condition to task condition?

RQ 5: To what extent does learners' perceived competence vary from task condition to task condition?

RQ 6: To what extent does learners' state anxiety vary from task condition to task condition? 


\section{Method}

\subsection{Participants}

A total of 154 first-year university learners from various majors (i.e., agro-biological resources, engineering systems, humanities, or library and information science) participated in this study, but because of their attendance and some procedural reasons such as missing data, the number of participants differed from task condition to task condition: 153 in the Individual Closed (IC), 135 in the Individual Open (IO), 135 in the Pair Closed (PC), and 154 in the Pair Open (PO) task. Their proficiency level was considered intermediate because all of them had studied English for at least six years prior to this study and successfully passed the entrance examination for a Japanese public university.

\subsection{Materials}

Two sets of materials were created: a questionnaire and a narrative writing task. The questionnaire was the same one used by Deci and Ryan (2004) to measure learners' affective reactions to a given task. The four affective factors measured are interest/enjoyment (four items), values/usefulness (five items), perceived competence (four items), and anxiety (four items), all of which are task-specific state variables. The questionnaire was administered before and after task performance, so slight changes in wording were made. It is a five-point Likert scale, ranging from 1 (strongly disagree) to 5 (strongly agree), with 17 items positively worded and the remaining three negatively worded. An open question in a free response format was also added at the end of the questionnaire in order to ascertain how the learners felt towards the questionnaire and the tasks.

One narrative writing task was designed. In this task, learners were basically instructed to describe four sets of cartoon strips presented to them; however, task conditions varied. In the closed tasks, learners needed to describe four cartoon strips either individually or in pairs (i.e., IC and PC). In the open tasks, they needed first to describe three cartoon strips presented to them and then create a last strip to finish the story of the cartoon (i.e., IO and PO). They were clearly informed that they were required to describe the last strip in a written form. Although some learners drew the last strip, it was completely excluded from scoring the performance. All of the participants were well aware that these four tasks were administered to assess their writing skills. They interacted with their partners in Japanese while working on the pair tasks. Thus, the task type was only one, but the four different conditions were taken into consideration.

\subsection{Procedures}

This study was conducted in compulsory English classrooms at a public Japanese university. The effects of task repetition was removed or reduced by assigning learners two tasks on two different occasions (June and September). Table 1 summarizes the order of task administration. Learners were first assured that the results of the study would not have any influence on their final grades, and they all agreed to participate in the research. After the announcement, sample cartoon strips were presented, followed by an explanation of how to complete the target task. The pre-task questionnaire was then 
distributed, and learners were asked to complete it in approximately five minutes. Next, students were allotted 15 minutes to perform the task. Immediately after the completion of the task, another five minutes were given to respond to the post-task questionnaire. Throughout the task performance, the use of dictionaries was strictly forbidden. As for the two pair tasks, pairing was determined simply by seating; that is, a learner cooperated with a classmate already seated next to him or her. This procedure was the same on all four occasions.

Table 1. Order of Task Administration Which Reduces Task Repetition

\begin{tabular}{lllll}
\hline & Task 1 (June) & Task 2 (June) & Task 3 (September) & Task 4 (September) \\
\hline Class 1 & IC & IO & PC & PO \\
Class 2 & IC & PO & IO & PC \\
Class 3 & IC & PC & PO & IO \\
Class 4 & IC & IO & PO & PC \\
\hline
\end{tabular}

\subsection{Data Analysis}

The mean scores of the motivational factors were calculated for the following $t$-tests and ANOVAs. Paired t-tests investigated whether learners' state motivation, perceived competence, and state anxiety varied from the pre-task condition to the post-task condition (RQs 1, 2, and 3). In this analysis, the data was not repeatedly analyzed; no adjustment of significant levels was necessary. With regard to RQs 3,4 , and 5, 4 (task conditions: individual closed and open tasks and pair closed and open tasks) $\times 3$ (state variables: motivation, competence, and anxiety) repeated ANOVAs were employed to examine how these three variables differed from task condition to task condition. This time, because the data was repeatedly analyzed, the significant level was modified to $p<.0083$. In terms of effect sizes, the effect size can be small when $r=.10$, medium when $r=.30$, and large when $r=.50$ (Field, 2005).

\section{Results and Discussion}

\subsection{Examinations of Changes in State Variables from Pre-Condition to Post-Condition}

\subsubsection{Changes in State Motivation}

The scores of interest/enjoyment and values/usefulness were combined to explore state motivation. This step was taken because these two factors are necessary components that formulate learner motivation (e.g., Crookes \& Schmidt, 1991; Gardner, 1985). Before giving an answer to RQ 1, the descriptive statistics of the pre- and the post-task motivation in the four different task conditions were calculated, and the results are presented in Table 2. The mean scores (the lowest is 3.074, but still above the half) show that learners in this study were moderately motivated to perform the tasks. 
Table 2. Descriptive Statistics of Motivation Levels in the Pre- and the Post-Task Condition

\begin{tabular}{lllllllll}
\hline & $\begin{array}{l}\text { Pair-closed } \\
(N=135)\end{array}$ & \multicolumn{2}{l}{$\begin{array}{l}\text { Pair-open } \\
(N=154)\end{array}$} & \multicolumn{2}{l}{$\begin{array}{l}\text { Individual-closed } \\
(N=152)\end{array}$} & \multicolumn{2}{l}{$\begin{array}{l}\text { Individual-open } \\
(N=135)\end{array}$} \\
\hline & $M$ & $S D$ & $M$ & $S D$ & $M$ & $S D$ & $M$ & $S D$ \\
\hline Pre-task & 3.097 & .719 & 3.074 & .716 & 3.207 & .638 & 3.143 & .720 \\
Post-task & 3.134 & .795 & 3.159 & .799 & 3.199 & .748 & 3.056 & .789 \\
\hline
\end{tabular}

Paired t-tests revealed that in three task conditions, no significant variation from the pre-task to the post-task condition was observed (in the pair-closed task: $t(134)=-.855, p=.394, r=.07$ (n.s.); in the pair-open task: $t(153)=-1.787, p=.076, r=.14$ (n.s.); in the individual-closed task: $t(152)=.208, p$ $=.836, r=.02$ (n.s.), while state motivation only significantly varied in the individual-open task ( $t$ (134) $=2.051, p=.042, r=.18$ ). Looking at the table above, it is noticeable that motivation significantly declined from the pre-task condition to the post-task condition. One tendency discovered by this study, was that the level of state motivation increased in the pair-closed and the pair-open task, while the level decreased in the individual-closed and the individual-open task. Although the results were not significant, this may suggest that learners' post-state motivation level is likely to develop positively in pair tasks.

In spite of the definition that state motivation is one's dynamic and momentary response (Tremblay, Goldberg, \& Gardner, 1995), this study found only limited variation in motivation from the pre-task condition to the post-task condition. The relationship between trait motivation and state motivation is here taken into consideration to explain this relatively stable characteristic of state motivation. It is argued that trait motivation governs state motivation (e.g., Gardner \& Tremblay, 1998; Tremblay, Goldberg, \& Gardner, 1995), and that a certain influence on trait motivation may be required to stimulate state motivation. The difficulty, however, is that trait motivation is a rather stable and enduring disposition that cannot be easily manipulated, especially in a condition in which situation-specific variables are emphasized. From the perspective of the trait and state distinction of motivation, this study implies that the role of trait motivation may be greater than that of task conditions in stimulating state motivation. Even though this may be the case, slight variations in state motivation were observed, so what contributed to the changes would be next investigated.

The focus here is placed on the difference between the closed and the open tasks because the open tasks, regardless of the pair or individual conditions, caused a larger change in state motivation than the closed tasks; a statistically significant variation was discovered in the individual-open task and a significant tendency was seen in the pair-open task $(\mathrm{p}=.076)$. It is presumed that these results are caused by task familiarity, which is a potentially strong factor for Japanese EFL learners. In their learning experiences in junior high and high school, Japanese learners are more frequently exposed to closed tasks (e.g., grammar exercises, drilling, and translation activities) mainly because they are put 
into a situation where they are required to prepare for entrance examinations for high school or university, and it is this exposure that results in task familiarity. When closed tasks are presented, learners can precisely predict what they are expected to do. In this study, describing four cartoon strips was what the participants were expected to do, and they grasped this task demand when the task was first presented. Their first impression might be that this task looked interesting or useless, and having this impression, they completed it. After the completion, they realized that their impression was closely linked with the feeling evoked during performance. As a consequence, state motivation did not show a dramatic change in the closed tasks.

As opposed to closed tasks, open tasks, to a larger extent, demand learners to be creative in order to successfully complete them. The learners in this study, for instance, were required to make up the final strip to conclude the story of the cartoon by referring to the three strips presented. Indeed, Albert and Kormos (2004) claimed creativity played an important role in performing tasks. The positive relationship between creativity and motivation was also found in Runco's (2005) discussion that creativity consists of cognitive, meta-cognitive, affective, and motivational variables. Based on their arguments, it is assumed that if learners can be sufficiently creative in carrying out open tasks, they may be able to be motivated to do them; however, conversely, if creativity is once threatened, state motivation may be also in danger. Besides, learners are less likely to engage in open tasks than closed tasks in their learning experiences, so there were some gaps between their impressions of the tasks and their retrospective feelings. State motivation, hence, varied from the pre-task condition to the post-task condition in open tasks.

Finally, the decrease in state motivation in the individual-open task needs to be accounted for in relation to creativity. Working individually, learners might have had difficulty creating the story of the cartoon, and this lack of creativity caused the decline of motivation in this specific task. The pair-open task, on the other hand, allowed a learner to cooperate with a partner to come up with the last cartoon strip. This cooperative work led to the slight increase in state motivation in the pair-open task.

\subsubsection{Changes in Perceived Competence}

This section attempts to respond to RQ 2 by examining whether learners' perceived competence varied from the pre-task condition to the post-task condition. Descriptive statistics of competence are presented in Table 3 below. The results of paired t-tests revealed that the level of perceived competence significantly varied from the pre-condition to the post-condition in the pair-closed task: $t(134)=-2.398$, $p=.018, r=.20$, in the pair-open task: $t(153)=-2.663, p=.009, r=.21$, and in the individual-closed task: $t(152)=3.894, p=.000, r=.30$, but not in the individual-open task: $t(134)=1.133, p=.259, r$ $=.10$ (n.s.). Exploring the mean differences in the table, it is observable that learners gained a sense of competence in carrying out the pair-tasks, whereas they lost it in performing the individual-tasks. 
Table 3. Descriptive Statistics of Competence Levels in the Pre- and the Post-Task Condition

\begin{tabular}{lllllllll}
\hline & \multicolumn{2}{l}{$\begin{array}{l}\text { Pair-closed } \\
(N=135)\end{array}$} & \multicolumn{2}{l}{$\begin{array}{l}\text { Pair-open } \\
(N=154)\end{array}$} & \multicolumn{2}{l}{$\begin{array}{l}\text { Individual-closed } \\
(N=152)\end{array}$} & \multicolumn{2}{l}{$\begin{array}{l}\text { Individual-open } \\
(N=135)\end{array}$} \\
\hline & $M$ & $S D$ & $M$ & $S D$ & $M$ & $S D$ & $M$ & $S D$ \\
\hline Pre-task & 2.363 & .650 & 2.403 & .639 & 2.495 & .644 & 2.391 & .635 \\
Post-task & 2.511 & .802 & 2.562 & .796 & 2.292 & .700 & 2.331 & .655 \\
\hline
\end{tabular}

Unlike the discussion of variations in state motivation regarding the account for the closed and the open tasks, the variations in perceived competence can be analyzed from the perspective of the pair and the individual tasks. There are two possible reasons to explain the increased level of perceived competence in the pair-tasks and the decreased level in the individual-tasks: an effect of motivation and a discrepancy between the past and the current level of English ability.

First, the changes in state motivation are responsible for the changes in perceived competence. The previous section discussed the tendency in which the level of learners' state motivation tended to increase in the pair-tasks, but decreased in the individual-tasks, and exactly the same tendency was witnessed in terms of perceived competence. Clément, Dörnyei and Noels (1994) and Deci and Ryan (1985), for example, proposed that motivation was significantly correlated with perceived competence. In other words, the development of motivation is related to that of perceived competence in the pair-tasks (i.e., the level of motivation tended to increase, and that of competence significantly increased), and also the decline of motivation is responsible for the decrease in competence in the individual-tasks (i.e., the level of motivation tended to decrease, and also that of competence significantly decreased in the individual-closed task).

The second reason concerns the gap between learners' past and current ability in English. This rather unique interpretation was based on the open responses in the questionnaires. Interestingly enough, some learners wrote that they realized they had lost grammatical knowledge and vocabulary that was accumulated when preparing for university entrance examinations. This kind of comment may imply why the level of competence declined from the pre-condition to the post-condition in the individual-tasks. Prior to task performance, they were highly confident with carrying out the tasks, but after completion, they recognized how many words or phrases they had forgotten even though they made enormous effort to in order to prepare for the examinations. Although the number of learners who wrote such comments was not so large, this interpretation may be justified especially for learners who succeeded in the entrance examination to a public university.

\subsubsection{Changes in State Anxiety}

Whether or not the level of learners' anxiety varies from the pre-condition to the post-condition (RQ 3) is investigated in this section. Similar to the variations in perceived competence, the results of t-tests demonstrated that state anxiety was more amenable to change in the pair-closed task $(t(134)=2.940, p$ 
$=.004, r=.25)$, in the pair-open task $(t(153)=5.486, p=.000, r=.41)$, and in the individual-closed task $(t(152)=4.811, p=.000, r=.36)$. The individual-open task, however, had no impact on the variation in anxiety $(t(134)=1.768, p=.079, r=.15$ (n.s.)). The descriptive statistics of anxiety in each task condition are presented in Table 4, and it is observed from these results that anxiety constantly diminished in both pair- and individual-tasks.

In a-year long study, Gardner et al. (2004) discovered that learners' state anxiety altered from time to time more dramatically than state motivation. In spite of their focus on the time effects on variations, their findings can be extended to task effects because state components were treated both in their study and in this study. Furthermore, state motivation in this study showed only a restricted change, but state anxiety showed more variability in various task conditions.

Table 4. Descriptive Statistics of Anxiety Levels in the Pre- and the Post-task Condition

\begin{tabular}{lllllllll}
\hline & \multicolumn{2}{l}{$\begin{array}{l}\text { Pair-closed } \\
(N=135)\end{array}$} & \multicolumn{2}{l}{$\begin{array}{l}\text { Pair-open } \\
(N=154)\end{array}$} & \multicolumn{2}{l}{$\begin{array}{l}\text { Individual-closed } \\
(N=152)\end{array}$} & \multicolumn{2}{l}{$\begin{array}{l}\text { Individual-open } \\
(N=135)\end{array}$} \\
\hline & $M$ & $S D$ & $M$ & $S D$ & $M$ & $S D$ & $M$ & $S D$ \\
\hline Pre-task & 2.969 & .960 & 3.076 & .919 & 2.985 & .943 & 2.859 & .960 \\
Post-task & 2.778 & .911 & 2.735 & .865 & 2.721 & .923 & 2.759 & .934 \\
\hline
\end{tabular}

In terms of state motivation and perceived competence, variations were found in different task conditions, but the level of state anxiety decreased in a consistent manner. As for the pair-tasks, the decreases can be relatively easily accounted for by borrowing the notion of L2 self-confidence. MacIntyre, Clément, Dörnyei and Noels (1998) identified two components involved in L2 self-confidence: a cognitive component corresponding to self-evaluation of skills (i.e., perceived competence) and an affective component referring to language anxiety. MacIntyre, Noels and Clément (1997) reported that these two components were highly correlated. The previous section showed the increased level of perceived competence in pair-tasks, and this increase is responsible for the decreased level of anxiety. Learners' self-confidence developed while engaging in the pair-tasks in which they cooperated with a partner to deal with difficulty. In this respect, the decreases in anxiety in the pair-tasks were positive and ideal.

On the other hand, it is rather difficult to construe the result of the individual-tasks. Most of the previous studies reported a negative relationship of anxiety with motivation and competence (e.g., Gardner, 1985; MacIntyre, Noels, \& Clément, 1997), but this study found a peculiar tendency that levels of state anxiety decreased together with state motivation and perceived competence. One assumption is that learners originally possessed positive feelings toward the individual-tasks as observed in a higher level of motivation than the pair-tasks. The positive attitude made them feel more anxious about performance because of the desire to perform the tasks well (Horwitz, E. K., Horwitz, M. 
B., \& Cope, 1986). However, once they found the tasks boring and useless (i.e., loss of motivation) or complex to work on individually (i.e., loss of competence), they did not seriously care about performance (i.e., loss of anxiety). In spite of the fact that this assumption cannot be supported by empirical research, it should be mentioned that anxiety is alleviated when motivation to perform a task well is threatened. In this respect, unlike the case in the pair-tasks discussed, the decrease in anxiety in the individual-tasks was negative and detrimental.

\subsection{Examinations of Variations in State Variables across Task Conditions}

This section attempts to give an answer to the question of whether learners' state variables vary from task condition to task condition before and after task performance (RQs 4, 5, and 6). Before discussion of this question, though, it needs to be noted that this section focuses on learners who completed all four target tasks $(N=132)$, and thus the descriptive statistics in the following tables are different from those provided in the preceding sections.

The data obtained before learners performed the tasks were first analyzed. The results of a 4 (task conditions: IC, IO, PC, and PO) $\times 3$ (state variables: motivation, competence, and anxiety) repeated AVOVA showed a significant interaction between the task conditions and the state variables $(F(4.181$, $547.648)=4.313, p=.002, r=.26)$, and also the significant main effect of the task conditions $(F$ $(2.714,355.511)=6.401, p=.001, r=.01)$ and the state variables $(F(1.546,202.516)=46.564, p$ $=.000, r=.01)$. These two main effects were moderated because significant interaction was observed. The simple main effect of the task conditions examined by one-way repeated ANOVAs indicated that the task conditions had a significant effect on the differences in the state variables, and the results are presented in Table 5.

Table 5. Results of ANOVAs for Task Conditions in the Pre-Condition

\begin{tabular}{|c|c|c|c|c|c|c|c|c|c|c|}
\hline & \multicolumn{2}{|l|}{$\mathrm{PC}$} & \multicolumn{2}{|l|}{$\mathrm{PO}$} & \multicolumn{2}{|l|}{ IC } & \multicolumn{2}{|l|}{ IO } & \multirow{2}{*}{ ANOVA } & \multirow{2}{*}{$\begin{array}{l}\text { Bonferroni's } \\
\text { post hoc } \\
(p<.0083)\end{array}$} \\
\hline & $M$ & $S D$ & $M$ & $S D$ & $M$ & $S D$ & $M$ & $S D$ & & \\
\hline \multirow{3}{*}{ Motivation } & \multirow{3}{*}{3.100} & \multirow{3}{*}{.723} & \multirow{3}{*}{3.083} & \multirow{3}{*}{.711} & \multirow{3}{*}{3.251} & \multirow{3}{*}{.598} & \multirow[b]{2}{*}{3.145} & \multirow[b]{2}{*}{.728} & $(2.559,335.274)$ & \multirow{3}{*}{$\mathrm{IC}>\mathrm{PO}^{* *}$} \\
\hline & & & & & & & & & $\begin{array}{l}=4.353 \\
p=.008, r=.19\end{array}$ & \\
\hline & & & & & & & & & $(2.863,374.995)$ & \\
\hline Competence & 2.375 & .649 & 2.413 & .644 & 2.519 & .640 & 2.405 & .633 & $\begin{array}{l}=3.120 \\
p=.028, r=.12\end{array}$ & n.s. \\
\hline \multirow[b]{2}{*}{ Anxiety } & \multirow[b]{2}{*}{2.968} & \multirow[b]{2}{*}{.963} & \multirow[b]{2}{*}{3.157} & \multirow[b]{2}{*}{.901} & \multirow[b]{2}{*}{3.044} & \multirow[b]{2}{*}{.926} & \multirow[b]{2}{*}{2.845} & \multirow[b]{2}{*}{.957} & $(2.882,377.506)$ & \multirow[b]{2}{*}{$\mathrm{PO}>\mathrm{IO}^{* *}$} \\
\hline & & & & & & & & & $\begin{array}{l}=6.356 \\
p=.000, r=.19\end{array}$ & \\
\hline
\end{tabular}


In terms of the effects of task conditions, attention is first paid to the individual-closed task that was considered more motivating and attractive than the pair-open task. This result can be attributed to English learning contexts in Japan. In junior high school, for instance, because learners do not possess sufficient language knowledge, they need to increase it through rote learning, memorization of new vocabulary, or translation exercises. They are also required to do these activities in order to successfully pass entrance examinations. In many cases, learning English in Japan takes place individually. Because of this learning context, learners may not be able to find any value working with a partner or in a group. Examining the answers in the free response questionnaire, it was noticed that some learners commented that they wondered why they were required to perform a writing task with a partner. A sense of value is a crucially important motivational variable (e.g., Crookes \& Schmidt, 1991) and also included in state motivation in this study. Therefore, if learners place more value on the individual-closed task, they are well motivated, but on the other hand, if they cannot find any value from the pair-open task, they are less motivated. Familiarity of task may also play a role in judging the tasks. The individual-closed task seemed to be most familiar, while the pair-open task was the least familiar in their learning experiences. Thus, learners felt more motivated to do the familiar task than the unfamiliar task. Second, learners' perceived competence did not differ from task condition to task condition. Since learners tended to underestimate their competence, this tendency might not cause any significant differences in competence prior to the task engagement. Third, the effect of pairing on the expansion of anxiety is not ignored in the discussion of pair tasks. As indicated earlier, pairing was decided by seating, so some learners did not know their partner well. They not only were pressured by working with the partner, but also were required to perform the tasks well. Furthermore, more cooperation and interaction with the partner was demanded in the pair-open task where learners needed to conclude the ending of the story by discussion. Similar to task motivation that is co-constructed by partners (Dörnyei, 2002; Kormos \& Dörnyei, 2004), state anxiety in pair tasks can be provoked by task participants. This accounts for the higher level of anxiety in the pair-open task than in the individual-open task.

Next, the data after learners actually performed the tasks were examined, and the results of a $4 \times 3$ repeated ANOVA indicated a significant interaction between the task conditions and the state variables $(F(3.879,508.181)=3.250, p=.013, r=.05)$. The main effects of the task conditions $(F(2.569$, $336.601)=4.230, p=.009, r=.26)$ and the state variables $(F(1.537,201.339)=37.375, p=.000, \mathrm{r}$ $=.34$ ) were also significant and were moderated since significant interaction was found. The following table presents the results of the simple main effect of the task conditions examined by one-way repeated ANOVAs. 
Table 6. Results of ANOVAs for Task Conditions in the Post-Condition

\begin{tabular}{|c|c|c|c|c|c|c|c|c|c|c|}
\hline & \multicolumn{2}{|l|}{$\mathrm{PC}$} & \multicolumn{2}{|l|}{$\mathrm{PO}$} & \multicolumn{2}{|l|}{ IC } & \multicolumn{2}{|l|}{ IO } & \multirow{2}{*}{ ANOVA } & \multirow{2}{*}{$\begin{array}{l}\text { Bonferroni's } \\
\text { post hoc } \\
(p<.0083)\end{array}$} \\
\hline & $M$ & $S D$ & $M$ & $S D$ & $M$ & $S D$ & $M$ & $S D$ & & \\
\hline & & & & & & & & & $(2.503,327.918)$ & \\
\hline Motivation & 3.134 & .801 & 3.177 & .780 & 3.228 & .711 & 3.059 & .793 & $\begin{array}{l}=3.042 \\
p=.038, r=.11\end{array}$ & n.s. \\
\hline Competence & 2.527 & .800 & 2.585 & .780 & 2.324 & .701 & 2.345 & .651 & $\begin{array}{l}(2.677,350.640) \\
=7.782, \\
p=.000, r=.35\end{array}$ & $\begin{array}{l}\mathrm{PC}>\mathrm{IO}^{* *}, \\
\mathrm{PO}>\mathrm{IC}^{* *}\end{array}$ \\
\hline Anxiety & 2.765 & .906 & 2.807 & .862 & 2.822 & .899 & 2.756 & .939 & $\begin{array}{l}(2.725,356.938) \\
=.398 \\
p=.735, r=.01\end{array}$ & n.s. \\
\hline
\end{tabular}

As for the differences in the state variables in each task, the lower levels of competence was observed in the two individual tasks, but they disappeared in the two pair tasks where learners' competence increased from the pre-condition to the post-condition. The significant effects of task conditions on perceived competence were observed in pair tasks. As opposed to the pre-condition, the variations in learners' sense of perceived competence were just surprising in the post-condition in which the two pair-tasks had a strong impact on the development of perceived competence (a significant tendency was also found between the pair-closed and the individual-closed $(p=.024)$ and between the pair-open and the individual-open $(p=.010)$ ). In general, pair or group work may be used to promote language performance through cooperation, but this study found that pair tasks had great potential to foster a sense of competence in learners. Learners' competence is most amenable to development in the pair-open task where they successfully interacted with a partner to complete the task and a sense of satisfaction was obtained. In terms of state motivation, the high tendency of learners' preference to the individual-closed task was still preserved in the post-condition, but any significant differences were not found, probably because of a slight increase in motivation in the pair-tasks. Finally, no significant effect of task conditions on the differences in anxiety was observed. It is assumed that anxiety may be more involved in the first impression of the tasks than in the actual task performance. In other words, learners did not have any control over their performance once they had completed the tasks, so the levels of anxiety were consistently the same across the tasks. 


\section{Conclusion}

Before concluding, one primary limitation should be pointed out. Since this study asked learners to repeatedly perform the same task type (i.e., narrative writing) four times, it was necessary to use four different cartoon strips. Some strips were easy and interesting to describe while others were less so. Subsequently, the cartoon strips may have had some effect on the changes in state variables. Although this limitation is difficult to overcome, future research should take other approaches that diminish the unexpected effects.

Two interesting findings of this study are as follows: (a) learners felt more competent in performing the pair tasks than the individual tasks, and (b) although some results were not significant, learners were strongly motivated to do the individual-closed task. Japanese learners are familiar with individual tasks because of their past learning experiences. If that is the case, teachers may not need to struggle to make tasks more complicated or novel, but instead should employ familiar tasks so that learning takes place more naturally. However, Japanese learners by and large feel incompetent in their skills and abilities. If teachers believe that enhancing a sense of competence is an emergent issue and the first priority, pair work will play a crucial role. This study supports the use of pair work, but this does not necessarily mean that individual work is less effective. It is still necessary to discern the relationships between task characteristics and state variables so as to facilitate better learning and teaching in the future.

This present study was conducted in compulsory classrooms at a Japanese local university. As mentioned earlier, Japanese learners are culturally and traditionally oriented toward individual tasks because of entrance examinations. If learners with different cultural, educational, and ethnic background are engaged in the four tasks used in this study, they may show totally different tendencies of changes in state variables. In addition, it is also interesting to focus on other skill areas, especially speaking which is more likely to affect learners' anxiety and competence in carrying out a given task. Further studies are certainly demanded to uncover learners' task-specific motivational variables.

\section{References}

Albert, À., \& Kormos, J. (2004). Creativity and narrative task performance: An exploratory study. Language Learning, 54, 227-310.

Boekaerts, M. (1986). The measurement of state and trait motivational orientation: Refining our measures. In J. H. L. van den Bercken, E. E. J. De Bruyn, \& Th. C. M. Bergen (Eds.), Achievement and task motivation (pp. 229-245). Lisse, Netherlands: Swets \& Zeitlinger.

Boekaerts, M. (1988). Motivated learning: Bias in appraisals. International Journal of Educational Research, 12, 267-280.

Clément, R., Dörnyei, Z., \& Noels, K. A. (1994). Motivation, self-confidence, and group cohesion in the foreign language classroom. Language Learning, 44, 417-448.

Crookes, G., \& Schmidt, W. R. (1991). Motivation: Reopening the research agenda. Language Learning, 41, 469-512. 
Deci, E. L., \& Ryan, R. M. (1985). Intrinsic motivation and self-determination in human behavior. NY: Plenum Press.

Deci, E. L., \& Ryan, R. M. (2004). Self-determination theory: An approach to human motivation and personality. University of Rochester, Department of Clinical and Social Sciences in Psychology. $\begin{array}{llll}\text { Retrieved January } & 14, & 2005, & \text { from }\end{array}$ http://www.psych.rochester.edu/SDT/measures/word/IMIfull.doc

Dörnyei, Z. (2002). The motivational basis of language learning tasks. In P. Robinson (Ed.), Individual differences and instructed language learning (pp. 137-158). Amsterdam: John Benjamins.

Field, A. (2005). Discovering statistics using SPSS (2nd ed.). London: Sage.

Gardner, R. C. (1985). Social psychology and second language learning: The role of attitudes and motivation. London: Edward Arnold.

Gardner, R. C., \& Tremblay, P. F. (1998). Specificity of affective variables and the trait/state conceptualization of motivation in second language acquisition. In R. K. Agnihotri, A. L. Khanna, \& I. Sachdev (Eds.), Social psychological perspectives on second language learning (pp. 31-52). New Delhi, India: Sage Publications.

Gardner, R. C., Masgoret, A. M., Tennant, J., \& Mihic, L. (2004). Integrative motivation: Changes during a year-long intermediate-level language course. Language Learning, 54, 1-34.

Hiromori, T. (2006). The effects of educational intervention on L2 learners' motivational development. JACET Bulletin, 43, 1-14.

Hiromori, T. (2012). Instructional practice that enhances English learners' motivation: Diagnostic use of motivation evaluation. Annual Review of English Language Education in Japan (ARELE), 23, 361-372.

Horwitz, E. K., Horwitz, M. B., \& Cope, J. (1986). Foreign language classroom anxiety. Modern Language Journal, 70, 125-132.

Julkunen, K. (2001). Situation- and task-specific motivation in foreign-language learning. In Z. Dörnyei, \& R. Schmidt (Eds.), Motivation and second language acquisition (pp. 29-41). University of Hawai'i, Second Language Teaching and Curriculum Center.

Koga, T. (2010). Dynamicity of motivation, anxiety, and cooperativeness in a semester course. System, $38,172-184$.

Kormos, J., \& Dörnyei, Z. (2004). The interaction of linguistic and motivational variables in second language task performance. Zeitschrift für Interkulturellen Fremdsprachenunterricht, 9. Retrieved April 19, 2006, from http://www.ualberta.ca/ german/ejournal/kormos2.htm

MacIntyre, P. D., Clément, R., Dörnyei, Z., \& Noels, K. A. (1998). Conceptualizing willingness to communicate in a L2: A situational model of L2 confidence and affiliation. Modern Language Journal, 82, 545-562.

MacIntyre, P. D., Noels, K. A., \& Clément, R. (1997). Biases in self-ratings of second language proficiency: The role of language anxiety. Language Learning, 47, 265-287. 
Masgoret, A. M., \& Gardner, R. C. (2003). Attitudes, motivation, and second language learning: A meta-analysis of studies conducted by Gardner and associates. Language Learning, 53, 123-163.

Robinson, P. (2001). Task complexity, task difficulty, and task production: Exploring interactions in a componential framework. Applied Linguistics, 22, 27-57.

Runco, M. A. (2005). Motivation, competence, and creativity. In A. J. Elliot, \& C. S. Dweck (Eds.), Handbook of competence and motivation (pp. 609-623). NY: Guilford Press.

Taguchi, T., Magid, M., \& Papi, M. (2009). The L2 motivational system among Japanese, Chinese, and Iranian learners of English: A comparative study. In Z. Dörnyei, \& E. Ushioda (Eds.), Motivation, language identity and the L2 self (pp. 66-97). Bristol: Multilingual Matters.

Tremblay, P. F., Goldberg, M. P., \& Gardner, R. C. (1995). Trait and state motivation and the acquisition of Hebrew vocabulary. Canadian Journal of Behavioural Science, 27, 356-370. 